\title{
TRABALHO E POLÍTICA NO COTIDIANO DA AUTOGESTÃo: A REDE
} JUSTATRAMA

TRABAJO Y POLÍTICA EN EL COTIDIANO DE LA AUTOGESTIÓN: LA RED JUSTATRAMA WORK AND POLITICS IN EVERYDAY LIFE OF SELF-MANAGEMENT: THE JUSTATRAMA NETWORK

Cris Fernández Andrada e Leny Sato

Universidade de São Paulo, São Paulo/SP, Brasil

\begin{abstract}
RESUMO
Este artigo apresenta uma pesquisa de doutorado que objetivou compreender as principais relações entre trabalho e política no cotidiano de uma rede autogerida. A Justa Trama reunia à época aproximadamente seiscentas pessoas, de sete empreendimentos econômicos solidários, de todas as regiões brasileiras, abarcando grande parte da cadeia produtiva do algodão agroecológico. Um extenso trabalho de campo, de caráter etnográfico, permitiu acompanhar as atividades políticas da rede entre 2010 e 2012. A filosofia da vida cotidiana de Agnes Heller foi o principal referencial teórico deste estudo. A rede revelou-se dialeticamente como organização de trabalho, cujo fim é gerar renda, e como organização política, de resistência ao modo de produção capitalista. Concluiu-se ainda que a política, no cotidiano da autogestão da rede, pode ser entendida como trabalho. E o trabalho, por sua vez, pode ser tomado como objeto da prática política dos trabalhadores.
\end{abstract}

Palavras-chave: psicologia social; trabalho; cotidiano; autogestão; economia solidária; práticas sociais.

\section{RESUMEN}

El artículo presenta una investigación doctoral que tuvo por objetivos comprender relaciones entre trabajo y política en el cotidiano de una red autogerida. Justa Trama reunía a la época aproximadamente seiscientas personas, de siete emprendimientos económicos solidarios, de todas las regiones de Brasil, abarcando gran parte de la cadena productiva del algodón agroecológico. Un extenso trabajo de campo, de carácter etnográfico, permitió acompañar las actividades políticas de la red entre 2010 y 2012. La filosofía de la vida cotidiana de Agnes Heller fue el principal marco teórico del estudio. La red demostró ser dialécticamente una organización de trabajo, con fines de generar renta, y una organización política, que busca resistir al modo capitalista de producción. Concluimos que la política, en el cotidiano de la autogestión de la red, puede ser entendida como trabajo, y que el trabajo puede ser tomado como objeto de la práctica política de los trabajadores.

Palabras clave: psicología social; trabajo; cotidiano; autogestión; economía solidaria; prácticas sociales.

\begin{abstract}
This article presents a doctoral research that aimed to discuss relationships between work and politics in the daily lives of a self-managed network. Justa Trama brings together about six hundred workers of seven economic enterprises from all regions of Brazil, it encompasses most of the links in the textile production chain from agroecological cotton plantation. An extensive ethnographic fieldwork enabled to monitor the political activities of the network between 2010-2012. The works of Agnes Heller about daily life are the main theoretical framework of this research. The network proved dialectically as an economic organization, whose purpose is to generate income, and as a political organization, resistance to the capitalist mode of production. It was also concluded that politics in the daily selfmanagement of the network can be regarded as inherent to the work, and the work can be taken as an object of political activity of the group of workers.
\end{abstract}

Keywords: social psychology; work; everyday life; self-management; solidarity economy; social practices. 


\section{Paradoxos da desigualdade: economia como fim ou como meio}

\begin{abstract}
Precisamos de uma psicologia social capaz de respeitar as capacidades coletivas expressas em saberes, práticas e ações organizativas, com a disposição e a competência de entrar na luta para as utopias, capaz de compreender as redes solidárias, a autogestão e a solidariedade. (P. K. Spink, 2008b, pp. 90-91)
\end{abstract}

"Nosso tempo é um tempo paradoxal", diz Boaventura de Sousa Santos (2002, p. 13), ao dispor lado a lado a opulência das novas tecnologias e os males sociais que para alguns pareciam superados formas degradantes de trabalho e de vida que acarretam adoecimentos e sofrimentos dos mais primários. Alçadas à categoria de revoluções - revolução da informação e da comunicação, revolução da genética e da biotecnologia - os recentes construtos humanos permanecem apartados da vida cotidiana de numerosas populações expostas às carências mais elementares: alimentos para o corpo e trabalho digno para garantir a sobrevivência (Patto, 2009).

Para Milton Santos (2004), eliminar a pobreza exige mudanças no próprio processo produtivo, "o que vale dizer, nas relações do homem com a natureza e dos homens entre si” (p. 68). Universos tão desiguais, riqueza e pobreza, como aponta o célebre geógrafo, são antagônicos e também complementares. Além disso, comungam da mesma autoria: a rica tecnologia e a miséria da fome e da doença são criações históricas, adventos humanos na colonização dos tempos e dos espaços. Frutos de uma produção mal distribuída, esses universos concentram, de um lado, potencialidades de produzir e viver cada vez mais e, de outro, carências e incertezas em relação às próximas horas. Paul Singer (2004) e Milton Santos (2004, 2008), entre outros estudiosos, há tempos apontam para a necessidade de rever o modelo econômico vigente: "o crescimento apenas pelo crescimento não é desejável. $\mathrm{O}$ crescimento deve ser subordinado aos dados sociais. ... Para isto, impõe-se uma reorganização radical dos objetivos da produção e, paralelamente, do consumo" (Santos, 2004, pp. 68-69). Ladislaw Dowbor (1998) resume bem o problema: "o objetivo central do desenvolvimento é o homem, enquanto a economia é apenas um meio" (p. 29).

\section{A crise do emprego e o ressurgimento da autogestão}

As profundas mudanças pelas quais passou o mundo do trabalho nas últimas décadas - em especial a partir da Crise do Emprego dos anos 90 - alavancaram o ressurgimento de relações de trabalho autogeridas, não apenas no Brasil (Coraggio, 2004; Sousa Santos, 2002). Desde então, como resposta às crises estruturais do capital (Antunes, 1999), trabalhadores esmeraram-se em gerar trabalho e renda por meio de um paradigma econômico não-capitalista, baseado em relações igualitárias e democráticas de produção, comercialização, crédito e consumo - a Economia Solidária (Gaiger, 2004; Singer, 2002).

Com vistas a resistir aos efeitos do desemprego ou da precarização das condições de trabalho, os trabalhadores da Economia Solidária tiveram que arquitetar ações cada vez mais complexas. Por meio da interação com diversos atores e instituições (governamentais e não governamentais), mulheres e homens de cooperativas, associações e grupos autogeridos, dos meios rural e urbano, buscam modificar e desenvolver novos modos de gerir o trabalho, de comercializar produtos e serviços, de obter crédito, de praticar intercooperação. O ânimo que os trabalhadores investem nestes processos é resistente, e as dificuldades são imensas. Trata-se, em suma, de gerar trabalho e renda e de tentar instituir outro modelo econômico, pautado pela autogestão, em meio às agruras e por entre as fendas do sistema capitalista (Morais \& Borges, 2010; Sousa Santos, 2002). Nesse sentido, o estudo aqui relatado inserese em um contexto de práticas sociais de resistência, engendradas por trabalhadores, na luta pelo direito ao trabalho, compreendido como um dos direitos humanos fundamentais ${ }^{2}$.

Hoje é possível encontrar muitos estudos e debates sobre os alcances e limites da Economia Solidária no complexo cenário econômico atual (Leite, 2009; Morais \& Borges, 2010; Souza, 2011). Há, no entanto, uma ideia de grande aceitação entre trabalhadores, militantes e estudiosos da área: a de que o desenvolvimento da Economia Solidária encontra-se condicionado pela expansão de redes de intercooperação entre suas organizações. Segundo Paul Singer declarou, em entrevista a Paulo de Salles Oliveira (2008):

Há muito tempo o movimento inteiro vem tentando $\underline{\text { construir redes, redes econômicas de cooperativas }}$ de segundo grau, cadeias produtivas organizadas. Pregamos isso aparentemente no deserto por anos, muito antes de surgir a Secretaria [Secretaria Nacional de Economia Solidária - SENAES], porque as cooperativas isoladamente são muito frágeis. A maior parte é de gente muito pobre, que não tem acesso a capital; tem difícil acesso ao mercado e também não tem acesso ao conhecimento. ... Agora, finalmente, depois de vários anos, estão surgindo cada vez mais 
redes de cooperativas. Um caso emblemático é a Justa Trama. (grifo nosso, p. 296)

Envolvidas com o tema da Economia Solidária desde 1999, sob a ótica da Psicologia Social do Trabalho, acompanhamos os primeiros esforços dos trabalhadores da Justa Trama em instituíla, em 2005. À época finalizávamos pesquisa de mestrado, desenvolvida na Cooperativa Univens, um de seus grupos fundadores (Andrada, 2009). O estudo aqui relatado foi proposto, portanto, como um desdobramento de pesquisa anterior, com o objetivo de compreender as principais relações entre trabalho e política no cotidiano dessa rede ${ }^{3}$.

\section{Justa Trama: uma breve apresentação}

A Cooperativa Central Justa Trama, composta à época da pesquisa por sete cooperativas ou associações singulares, foi criada em 2005 e formalizada em 2008 como uma cooperativa de segundo grau, cuja sede localiza-se em Porto Alegre. Reúne cerca de seiscentas pessoas, de empreendimentos autogeridos de todas as regiões geográficas do país. Foi proposta por seus trabalhadores, a maioria mulheres de baixa renda, como uma ampla rede de intercooperação, baseada na cadeia produtiva têxtil do algodão agroecológico, com vistas a gerar mais trabalho e renda aos grupos de base. Abarca grande parte da cadeia produtiva do algodão agroecológico, do plantio à confecção final.

No arranjo da rede, portanto, encontram-se associados em autogestão trabalhadores dos meios rural e urbano, de diversos setores da economia, de atividades como a agricultura, a indústria e o artesanato que, juntos, fabricam os insumos que resultam nos produtos da Justa Trama: peças de vestuário, bolsas, brinquedos, jogos e adereços de algodão agroecológico. Esta integração multidimensional, aliás, é aspecto central na identidade da rede.

À época, a Justa Trama era composta pelos empreendimentos representados na Figura 1: duas associações de pequenos agricultores familiares, uma fábrica recuperada de médio porte e quatro pequenas cooperativas, localizadas nas periferias de grandes centros urbanos.

Figura 1. Localização dos empreendimentos da rede e respectivas atividades produtivas

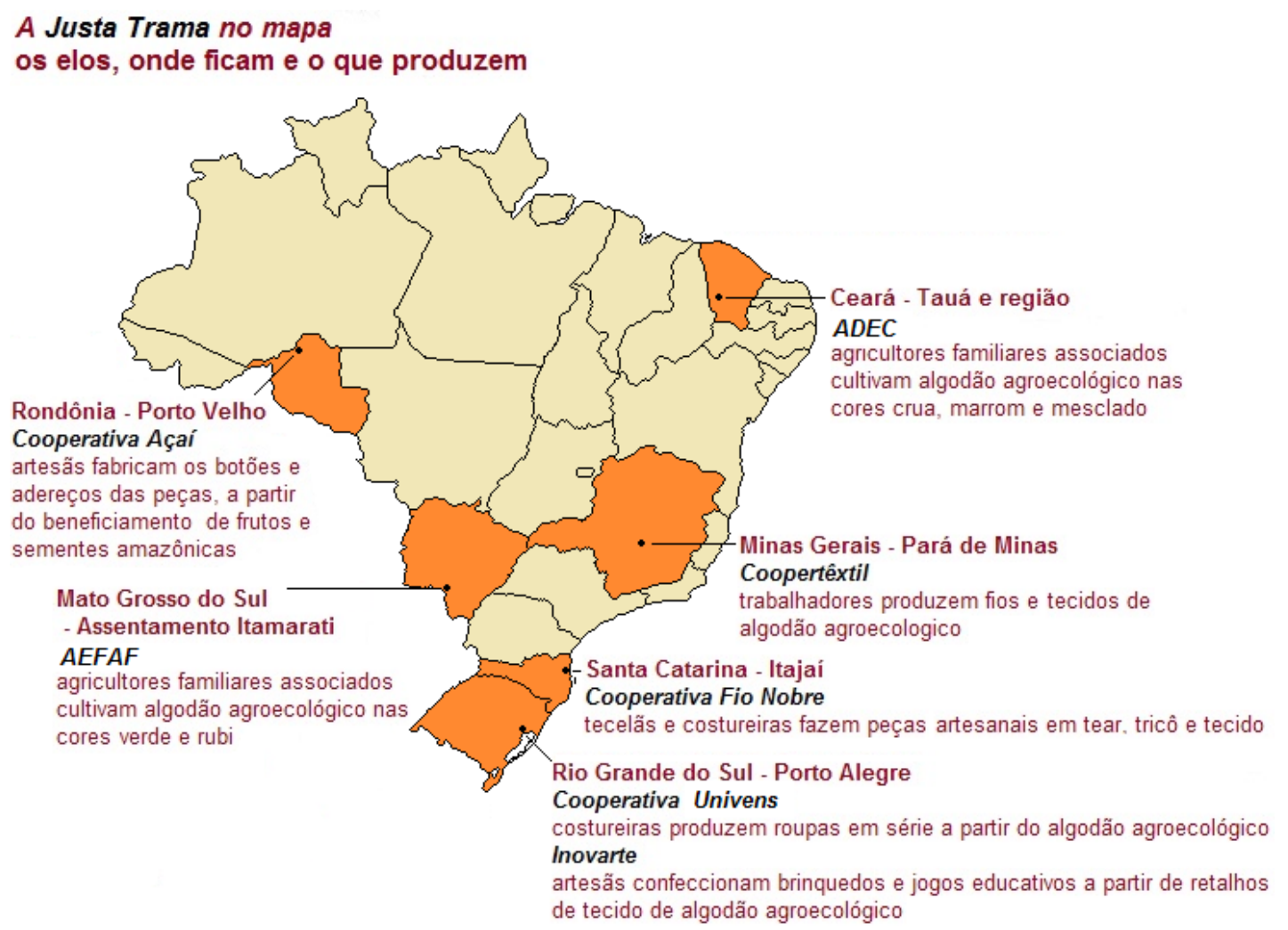


De modo geral, a rede tem um desempenho econômico estável e modesto, em curva levemente ascendente, quando cotejado a períodos anteriores ${ }^{4}$. Em 2012, uma das associadas afirmou: "conseguimos nos planejar e cumprir bem [o planejamento anual]". Exemplo disso é que foi possível escoar toda a produção do período, remunerar o trabalho e ainda discutir o que fariam com as sobras que, se não eram muitas, possibilitavam reinvestimentos. Ou seja, atualmente a rede é capaz de pagar seus custos, facilitar a seus grupos o acesso a bens materiais e simbólicos importantes (como máquinas, equipamentos e cursos de formação continuada), gerar mais trabalho e aumentar a renda de seus associados, ainda que nenhum dos empreendimentos dependa exclusivamente dela.

Rede presente em outras redes, a Justa Trama participa politicamente de vários fóruns locais, nacionais e internacionais, não apenas do movimento da Economia Solidária, para o qual se tornou importante referência, mas também de ações políticas ligadas à promoção da agroecologia e da segurança alimentar. Desde o início a Central conta com vários parceiros, instituições governamentais e não-governamentais (Cruz, 2010; Metello, 2007).

A rede possui uma coordenação geral formada por representantes de todos os empreendimentos ou elos, como são chamados pelos trabalhadores. Tratase de uma direção colegiada, eleita a cada três anos, que tem por tarefas planejar e coordenar as atividades de gestão econômica e política da rede. Além da assembleia anual, o grupo reúne-se a cada três ou quatro meses, em encontros que costumam durar ao menos um final de semana. Há o empenho de intercalar a sede dessas reuniões para facilitar a participação de diferentes trabalhadores, já que são momentos importantes do ponto de vista micropolítico.

Com efeito, o grupo não adota no cotidiano um modelo rígido de gestão, nem conta com uma equipe de técnicos que concentra estas atividades. Pelo contrário, a gestão da rede ocorre em meio aos processos produtivos de cada elo, conforme demandas e tarefas previamente agendadas e acordadas, já que não há associados destacados exclusivamente para cuidar das tarefas administrativas. Esta escolha do grupo, no entanto, não é consensual. Como disse um associado, "todos fazem tudo, e isso é bom e ruim ao mesmo tempo". A gestão da rede parece, decerto, resultado de interações cotidianas fluidas, ancoradas em relações horizontais, de confiança e de reciprocidade, que respondem com notável plasticidade às demandas existentes. Para a tomada de decisões cotidianas e a resolução de problemas imprevistos, por exemplo, os associados envolvidos com a situação consultam rapidamente uns aos outros, por meio de mensagens eletrônicas e contatos telefônicos. Esse trabalho, não remunerado, é realizado em meio à produção ${ }^{5}$.

Vale destacar ainda que a rede está inserida em um setor da economia capitalista altamente competitivo - o setor têxtil e da confecção - conhecido por condições insalubres de trabalho e por práticas ilegais e desumanas de exploração de mão de obra. Sabe-se também que esse setor vem sendo afetado especialmente pela expansão da economia chinesa (M. Oliveira, 2009). A opção da Justa Trama, neste tocante, no entanto, é estratégica: o grupo direcionou seus produtos a um mercado alternativo, que experimenta crescimento, o comércio justo ou fair trade (Cruz, 2010). De acordo com um levantamento realizado pela instituição Faces do Brasil, em 2010 a rede já vendia cerca de $50 \%$ dos produtos em espaços da Economia Solidária e outros $22 \%$ no mercado institucional (camisetas e sacolas para eventos). Portanto, trata-se de crescer economicamente, mas com uma consideração vigilante a princípios políticos do grupo. Exemplo disso é o modo como são formados os preços dos produtos da Justa Trama, processo identitário desse coletivo, adiante apresentado:

O que a gente não quer, de jeito nenhum, é repetir o que está aí [trabalho precário]! ... Se não for pra ser melhor que o capitalismo, não vale a pena. Não digo no começo de uma cooperativa, que tu está te estruturando. Ali você tem que dar tudo, te sacrificar mesmo. Mas depois tem que ser melhor ... Melhor pra saúde, pras condições de trabalho, de vida de cada um. (Diário de Campo, Porto Alegre, 17/10/2010)

Pode-se dizer, em suma, que a Justa Trama representa a articulação em rede de trabalhadores organizados em contextos específicos, orientados por ações políticas comuns, basicamente a resistência aos ditames de uma economia capitalista que os excluiu do mercado de trabalho ou tendia a fazê-lo, e a construção de uma alternativa de trabalho justa e democrática. Esses trabalhadores experimentaram o desalento de um trabalho precário, instável e penoso na falta de recursos para enfrentar a seca do sertão, nas horas vergadas sobre a máquina de costura como trabalhadoras autônomas ou no desemprego com a falência da fábrica capitalista, que confiscara economias e direitos trabalhistas.

É fato também que os grupos que formam a Justa Trama contam em seus quadros com lideranças fortes e democráticas, formadas nos movimentos sociais dos anos 80 e 90, com destaque para o meio sindical e eclesial de base. A organização política em rede desses coletivos já é, de um lado, evidência da sobrevivência dos grupos singulares, conquistada por anos de lutas 
locais, e, de outro, do desenvolvimento da Economia Solidária brasileira (Cruz, 2010). Do processo histórico de constituição do coletivo da rede trataremos adiante.

\section{Os meios no centro: o método e o trabalho de campo}

Esta breve apresentação da Justa Trama revela por si um dos matizes dominantes da pesquisa: o permanente esforço de síntese que tivemos que fazer diante de tanto - tantos empreendimentos, pessoas, lugares e diversidades ${ }^{6}$. A complexidade do objeto, aliada ao interesse pelos pontos de interface entre Antropologia e Psicologia Social, nos levou a dedicar muito tempo ao trabalho de campo e à discussão metodológica, apresentados em detalhe na tese que deu origem a este artigo (Andrada, 2013). Como referencial metodológico, tomamos a etnografia (Magnani, 2009), em razão do fecundo diálogo que estabelece com o enfoque psicossocial (Andrada, 2010). Buscamos apoio especificamente no conceito de etnografia multissituada, proposto pelo antropólogo George Marcus (1995), principalmente para ajudar a responder à questão: "como fazer etnografia quando o campo é plural?".

A concepção de pesquisa no cotidiano como relação social também foi uma premissa metodológica relevante. Nesse sentido, adotamos como referências os trabalhos psicossociais de Leny Sato e Marilene Proença de Souza (2001), Mary Jane Spink (2007) e Peter Spink (2008a). Eles recuperam a compreensão dos trabalhos de campo em pesquisas de Psicologia Social como uma prática de conversa e de debate, a partir de uma inserção horizontal do pesquisador no cotidiano das situações de pesquisa (P. K. Spink, 2008a).

Como ferramentas, fizemos uso de observações etnográficas combinadas a entrevistas abertas e de longa duração, revistas à luz do enfoque etnográfico. As viagens resultaram em um extenso Diário de Campo, baseado em mais de trinta dias de convívio com os trabalhadores, em regime de imersão cotidiana. De modo geral, buscamos compreender como os trabalhadores da rede conciliam as demandas do trabalho e da gestão com aquelas alusivas à política; que alimentos e entraves encontram nesses processos e que recursos desenvolveram para operar com eles no cotidiano. Também nos dedicamos ao exame do processo histórico de instituição da Justa Trama. Ouvimos detidamente os trabalhadores sobre os marcos históricos do desenvolvimento da rede, os princípios que norteiam as práticas do grupo, o papel das relações políticas de parceria, entre outros aspectos. Foram realizadas onze viagens (três internacionais) e seis entrevistas (uma delas coletiva), entre 2010 e 2012.

A ideia inicial era seguir a "trilha do algodão", medida comum entre pesquisadores que estudam redes produtivas. Nesse caso, a rota em campo está previamente traçada pelo processo produtivo: primeiro vai-se ao grupo responsável pelo plantio do algodão, depois ao empreendimento que o fia e tece etc. Mas o encontro com as diversidades da experiência nos fez rever a rota e o foco da atenção em campo em meio aos trabalhos. Após as primeiras viagens, a "trilha do algodão" pareceu uma abstração não condizente com nosso objeto - os processos políticos cotidianos da rede. Assim, mais que visitar os elos em separado, para esta pesquisa fazia mais sentido acompanhar os encontros entre os empreendimentos - a agenda política da rede -, o que nos levou muitas vezes para além de suas fronteiras geográficas.

\section{Principais resultados}

As experiências de campo nos permitiram confirmar que os lugares políticos da rede não são os elos em separado, mas aqueles onde se encontram de fato, representados e ativos, todos eles - um primeiro achado da pesquisa. Ali comungam de uma identidade coletiva e, desse lugar compartilhado, se dedicam à gestão do empreendimento que juntos criaram e sustentam dia a dia. Vimos ainda nas primeiras viagens que participar da Justa Trama tem um sentido importante de resguardo e de valorização das especificidades de cada grupo, não só em termos econômicos, mas também políticos e culturais. Esse é um forte ganho simbólico conferido pela rede ao desenvolvimento local de cada região. Também representa, de modo geral, um estímulo à participação nela, como uma modalidade de intercooperação que respeita as autonomias e dá visibilidade às singularidades de cada coletivo e localidade, ao passo que também se beneficia delas, enquanto rede, em termos políticos e econômicos. Esse achado é relevante na medida em que nem sempre participar de redes tem significados benfazejos: "As redes solidárias, por exemplo, podem servir para transformar desigualdades, quebrar barreiras de escoamento comercial e garantir acesso às informações, como também podem servir para reproduzir relações desiguais" (P. K. Spink, 2008b, p. 88).

Também na cadência do campo cresceu o interesse por compreender como os trabalhadores conseguem fazer tanto, em termos políticos e históricos, com poucos recursos e num meio tão 
adverso. José Ribeiro (Coopertêxtil) resume bem o problema: "Os maiores desafios que eu vejo vêm de que nós não somos regra, nós somos exceção. ... E ser exceção é ter que enfrentar um mundo de coisas contrárias". Essa questão tornou-se uma ótima bússola em campo. Porque buscar pelas relações entre trabalho e politica podia ser um postulado teórico formalmente claro, mas revelou-se duro e impalpável perante a plasticidade do cotidiano com os trabalhadores.

A inquietação por compreender como os trabalhadores da rede conseguem construí-la e sustentá-la no cotidiano pedia, pois, uma teoria dialética sobre a História, que nos deixasse seguir os movimentos do grupo, de perto e sem pressa, e que fosse condizente com nossas concepções marxistas de partida. Ou seja, para ser leal à experiência do campo, era preciso contar com lentes interpretativas que permitissem a percepção acurada das pessoas em face às estruturas, na consideração dos processos históricos da (re)produção da vida cotidiana dos trabalhadores. Nesse sentido, o referencial teórico adotado - a obra sobre cotidiano e história de Agnes Heller (2008) - representou uma resposta a uma necessidade do campo.

Os achados da pesquisa foram organizados em casos sobre o cotidiano, com base na experiência etnográfica, e em narrativas sobre a história da rede, amparadas nas entrevistas com os trabalhadores. Diante da impossibilidade de expô-los integralmente, ilustraremos a seguir algumas passagens e sínteses a respeito desses dois conjuntos.

\section{Casos sobre o cotidiano da rede}

O tom dos relatos é basicamente etnográfico, daí a escolha do nome de seus subtítulos, Diários e Notas. Por meio dos Diários, mais extensos, buscamos evidenciar, por exemplo, o contraste entre o cotidiano de um elo e o cotidiano da rede, em termos políticos.

Além de revelar a complexidade das idiossincrasias locais, as viagens de campo evidenciaram que, além de participar da Justa Trama, cada empreendimento que a compõe interage política e economicamente com outros coletivos, fóruns e redes. Na incursão a Pará de Minas (cidade-sede da Coopertêxtil), vimos ainda que a rede exerce uma importância política e econômica não apenas diferente para cada elo, como também desigual. Mas essa e outras incursões ensinaram que se trata de um equilíbrio dinâmico, historicamente. A depender de novas circunstâncias (como o advento de outra cadeia solidária, estimulada pelo grupo), a relevância da rede frente a cada elo muda sensivelmente.

Nas Notas de Porto Velho focalizamos passagens da Assembleia da Central. Elas mostraram como o trabalho e a gestão podem ser vistos como objeto de prática política na autogestão do grupo, como propõem as premissas desse modo de organização de trabalho. Uma organização sempre provisória, promovida pelos trabalhadores, a partir dos recursos de que dispõem, entre o possível das circunstâncias e o desejável de seus projetos e princípios.

No caso da incursão a Itajaí, especificamente, o objetivo foi visitar outro elo da rede (Fio Nobre) e, ali, conhecer as dificuldades econômicas enfrentadas pelos trabalhadores. Refletimos com eles sobre um debate que toca a todo o coletivo da rede: "a Justa Trama é um meio [político] elou um fim [econômico]?" Essa questão é um "falso dilema", já que não se trata de algo unidimensional, e o grupo demonstra saber disso, em práticas e discursos. $\mathrm{O}$ debate se inscreve na desigualdade entre as ênfases dadas, nas ações cotidianas dos trabalhadores, às dimensões política $\mathrm{e}$ econômica da autogestão da rede.

Já as viagens a Montevidéu (Uruguai) e a Badalona (Espanha) evidenciaram como os interesses políticos dos trabalhadores da rede ultrapassam as fronteiras geográficas de seus empreendimentos. Distantes de seus lugares de origem, representantes da Justa Trama estabelecem ou atualizam relações com parceiros políticos da Economia Solidária de outros países. No caso específico da viagem a Montevidéu, foi possível acompanhar ainda como operam as habilidades políticas ${ }^{7}$ dos trabalhadores, investidas ali em construir outra rede, de contornos ainda maiores, inspirada na Justa Trama - a cadeia solidária binacional do PET.

Em resumo, os casos expressam, entre outras coisas, como a participação numa rede nãocapitalista permite aos trabalhadores antever ou amainar dificuldades que sem ela poderiam ser ainda mais ameaçadoras. De modo geral, revelam também a presença de uma tensão constante no cotidiano, entre a necessidade de resistir aos efeitos nocivos do embate com o sistema capitalista e a necessidade de criar, de modo tático mas também estratégico, métodos, ações e projetos, eminentemente políticos, para enfrentá-los (Certeau, 1994). Os relatos também deram visibilidade aos valores e princípios que orientam as práticas dos trabalhadores, notadamente informados por interesses humano-genéricos (Heller, 2008), como a luta pela agroecologia e o estímulo à formação de outras redes solidárias. 
Figura 2. Casos sobre o cotidiano da rede, com base na experiência etnográfica

\begin{tabular}{|c|}
\hline 1 - Problema de um é problema de todos: a crise do algodão atinge os primeiros elos \\
\hline 2 - Sócio na rede é aliado: quem compra propõe pagar mais \\
\hline 3 - Participação política: problema e solução \\
\hline 4 - Ser ou não ser Justa Trama: "os dois projetos" \\
\hline 5 - Estoque, comercialização, finanças: a gestão tratada politicamente \\
\hline 6 - "Esse é o nosso dilema": como aumentar a renda sem elitizar os produtos \\
\hline 7 - Viagem a Quixadá: encanto e desalento no encontro entre os elos \\
\hline 8 - O passeio pelas modinhas: reencontro com o trabalho precário \\
\hline
\end{tabular}

Como exemplo, expomos a síntese de um desses casos, que ilustra a tensão acima mencionada, materializada no debate sobre a composição de preços dos produtos da rede.

“' Esse é o nosso dilema': como aumentar a renda sem elitizar os produtos” - Miriam (Inovarte) apresenta um estudo de custos detalhado. Nele destaca-se um dado preocupante: alguns produtos têm custo igual ou maior que o valor de venda, principalmente peças artesanais. ... Segue-se uma discussão importante, com forte participação de todos: "Tem que aumentar o preço, estudando bem os custos!”, alguém dissera. Ismael (Fio Nobre): "Tem que olhar o mercado. Eles têm saída mesmo com esses preços? Terão se ficarem mais caros?". Nelsa (Univens): “A cadeia tem que vir pra melhorar a vida da gente". Terezinha (Univens): "Mas tem outra coisa, quando criamos a Justa Trama dizíamos que queríamos fazer produtos que pudéssemos comprar'. Nelsa (Univens): "Esse é o nosso dilema". Dalvani (Açaí): "Mas, gente, quem tem fome tem pressa, não tem ideologia. ... Se há alguém disposto a pagar mais pelo nosso produto $e$ melhorar nossa vida, é isso que temos que buscar". (Diário de Campo, Fortaleza, 08/08/2010)

O processo de composição de preços dos produtos da Justa Trama é resultado de um duplo compromisso dos trabalhadores, vivido por eles como um dilema, dado o desafio de executá-lo. De um lado, trata-se de vender os produtos a preços não-elitizados para permitir o acesso a eles de pessoas de todas as classes sociais, e assim manter o potencial transformador da rede. Como critério de vigilância do cumprimento deste princípio, os associados perguntam-se periodicamente se eles próprios poderiam pagar tais valores por uma vestimenta. De outro, procuram operar com preços que permitam gerar a melhor remuneração possível. Interessante notar que em vez de seguir medidas comumente adotadas por empresas atuantes no mercado capitalista, o grupo adotou um recurso micropolítico para definir os valores de seus produtos, de modo a contemplar seus princípios e interesses. A partir de um estudo de custos, uma comissão de trabalhadores estipula o preço final de cada item, tomando em consideração o tempo de produção e um valor de remuneração mínima mensal para cada trabalhador(a), definido coletivamente. Nesse sentido, é possível afirmar que se trata de um vivo exemplo de adequação do trabalho às necessidades das pessoas, $\mathrm{e}$ não o contrário. Ou ainda, em outros termos, que o trabalho aqui comparece subordinado, ainda que em parte, aos princípios, métodos e ações políticas do coletivo de trabalhadores.

Com base nos casos citados, podemos afirmar em suma que ambiguidades e contradições assolam o grupo constantemente no cotidiano de trabalho, que se esmera em construir projetos e ações para enfrentálas. Materializam-se, por exemplo, no esvaziamento crescente dos fóruns políticos ou na tensão operada pelo mercado capitalista, que aceita melhor os produtos da rede quando embalados ao gosto das elites. Há encanto nos olhos das costureiras e tecelões ao conhecerem as flores do algodão, ao percorrerem pela primeira vez o elo que une o trabalho deles à terra e ao trabalho dos agricultores. E há também desalento, quando constatam as condições precárias de vida e de trabalho deles, hoje seus sócios na rede.

Cada caso é portador, portanto, de uma história de luta cotidiana do grupo pelo direito ao trabalho 
coletivo em condições dignas, num cenário que constantemente os tensiona à exclusão da miséria ou à corrupção de seus valores mais caros. Para isto, do ponto de vista político, contam uns com os outros identidade de grupo e como classe trabalhadora - com um grau incomum de consciência da realidade em que vivem e das relações de poder nela imbricadas e com valores humano-genéricos, assentados numa história comum, de resistência e de criação históricas. No relato dos casos, nosso maior esforço foi de descrever o que e como fazem para resistir e fazer História no entremeio dessas tensões. E, nesse sentido, os aspectos sublinhados acima exercem papel crucial.

\section{Narrativas sobre a história da rede}

Por meio das narrativas dos trabalhadores, buscamos reconhecer a conjuntura e as motivações que orientaram a organização da Justa Trama. Tratamos de identificar ainda aspectos considerados marcos do percurso, como as dificuldades enfrentadas, o estabelecimento de valores, parcerias, além dos modos de fazer do grupo e de operar das lideranças políticas.

A Justa Trama nasceu de uma conjuntura politica.. ... Nós somos de 30 anos de militância, nós não nascemos ontem. Nós também soubemos aproveitar uma conjuntura política. ... Nós nunca fizemos um encontro em que a primeira manhã não fosse análise de conjuntura. (Idalina, Fio Nobre)

Em princípio, a proposta da rede surgiu como uma possibilidade de melhorar as condições de trabalho das cooperadas da Univens. Este pequeno grupo de costureiras gaúchas, organizado em autogestão, enfrentava dificuldades no cotidiano, tinha consciência política das contradições vividas e da possibilidade de serem sujeitos de um processo de mudança também. Embora a cooperativa já tivesse conquistado a estabilidade econômica, garantindo a seus membros renda acima dos patamares médios do mercado, era preciso diminuir as altas jornadas de trabalho, em nome da saúde das costureiras (Andrada, 2009).

Mas os relatos das trabalhadoras revelam também uma conjuntura complexa que permitiu o surgimento e a organização da rede Justa Trama. Em 2004, ano em que começou a articular-se efetivamente a Justa Trama, a Economia Solidária brasileira experimentava grande crescimento, especialmente em termos políticos e institucionais (Souza, 2011). É de 2003 a constituição da Secretaria Nacional de Economia Solidária (SENAES), ligada ao Ministério do Trabalho, e do Fórum Brasileiro de Economia Solidária (FBES), por exemplo.

Em suma, quanto aos aspectos facilitadores do surgimento da Justa Trama, as trabalhadoras assinalam, de um lado, a importância do Fórum Brasileiro de Economia Solidária (FBES) como espaço público de encontro do movimento e das futuras lideranças da rede. De outro, o papel de instituições de representação e fomento da Economia Solidária, ligadas ao movimento sindical (ADS-CUT e UNISOL Brasil), na medida em que contribuíram técnica, financeira e politicamente com o projeto, facilitando a articulação dos empreendimentos.

No entanto, as trabalhadoras recordam os primeiros encontros em torno do projeto em meio a muitas dificuldades. Nelsa (Univens) lembra que as primeiras reuniões sobre o tema "tinham muita impossibilidade": "Faltava tear, faltava algodão, faltava tudo." Ou ainda, "não existia como ter empréstimo, não existia nada". Dalvani (Açaí), ao conhecê-las, solidariza-se: "as pessoas não acreditavam naquilo. ... Era complicado". Ainda que já se falasse da necessidade de os trabalhadores da Economia Solidária organizarem-se em redes, não havia exemplos ou tutoriais a seguir. E, como costuma ocorrer com as criações anti-hegemônicas, logo que surgem geram resistências, mesmo entre pessoas favoráveis à ideia.

Importa destacar que, no horizonte das circunstâncias, as trabalhadoras perseguiram as poucas possibilidades vislumbradas para construir a cadeia. As primeiras ações em rede datam de 2005, quando o grupo organizou-se em torno do Fórum Social Mundial (FSM), realizado em Porto Alegre. $\mathrm{Na}$ ocasião, instituíram uma grande intercooperação, embrião da Justa Trama, para produzir as sessenta mil sacolas do evento. Para isto, coordenaram o trabalho de produção e de gestão de trinta e cinco empreendimentos de quatro estados brasileiros.

Colocamos que ia ser com todos os empreendimentos da Economia Solidária que quisessem. Foi uma loucura! ... E olha, foi a experiência mais linda que a gente viveu de tantos coletivos em tão curto prazo poder entregar um produto como esse. ... Talvez de todos os processos que eu tenha vivido até então, tenha sido o mais democrático, o mais participativo ... a gente conseguiu fazer tudo isso e a sacola pro Fórum Social custou menos do que no ano anterior, e nós todos ganhamos o dobro dos preços praticados pelo mercado naquela época. (Nelsa, Univens)

Ao mesmo tempo em que colocaram em marcha a primeira ação econômica da rede, as trabalhadoras inscreveram uma Oficina no mesmo evento, pautando 
a experiência como debate político no movimento da Economia Solidária. Ou seja, mesmo sem terem angariado os recursos essenciais - como o algodão e o tear industrial -, elas disparavam as ações possíveis, especialmente no plano político. Esse fato pareceu relacionado ao tino político e à leitura perspicaz das circunstâncias por parte das trabalhadoras. Vale frisar que parte dessas circunstâncias já havia sido provocada por elas. Ao final dessa oficina, por exemplo, elas travaram contato com representantes da SENAES (Secretaria Nacional de Economia Solidária) em busca de recursos ao projeto e em meio ao entusiasmo por ele despertado ali, o que acabou se concretizando. Também foi possível dali em diante contar com o apoio de outras instituições, nacionais e internacionais, representadas no evento. As adesões de outros parceiros e outras ações políticas semelhantes, por sua vez, permitiram a aproximação de novos apoiadores, num circuito crescente e em espiral, observável até os dias de hoje.

Ou seja, seguir o rastro da história da Justa Trama é também reconhecer, em seus oito anos de existência, o estabelecimento de muitas relações de apoio e de parceria, com instituições diversas, públicas e nãogovernamentais, não apenas por parte da rede como um todo, como também dos empreendimentos que a compõem. Parceiros e apoiadores são constantemente citados pelos trabalhadores, em geral, num ânimo de reconhecimento, também pelo alto grau de respeito e de autonomia política que regem estas relações.

Vale citar rapidamente os marcos da história da rede, segundo os entrevistados. Neste tocante, eles destacaram situações alusivas à constituição de um sentimento de grupo e a um empoderamento crescente como trabalhadores. Além de deterem o controle compartilhado dos meios de produção em seus empreendimentos de base, contavam agora com o controle do processo produtivo em maior escala. Viram-se livres não apenas dos patrões, como outrora, mas também dos atravessadores. Isso, no entanto, carrega novas exigências: "Teve todo um processo de reconstituir conceitos, desde os valores econômicos das peças, o jeito de fazer" (Nelsa, Univens). Como exemplos, ela cita os processos de criação das primeiras peças e da escolha do nome da rede, e, neles, os impactos causados nas trabalhadoras:

Virou a cabeça, e isso é maravilhoso! É maravilhoso você ver que você pode criar. Criar, sabe?! E é lógico, depois da criação, criar a modelagem... Então $\underline{\text { isso }}$ fez um bem tremendo pra nós ... E a nossa maior descoberta é que, desde que a Justa Trama surgiu até hoje, as roupas que a gente mais vende e que continuam no nosso catálogo são as roupas que a gente inventou. (Nelsa, Univens, grifo nosso)
Ao ouvi-la, foi inevitável pensar nessas situações como resgates da função teleológica do trabalho, tão comprometida nas organizações capitalistas, como apontaram Marx (1980) e Lukács (2010). Outros marcos no percurso do grupo são os encontros entre os diversos elos - situações importantes na promoção da integração do coletivo e na integração de cada trabalhador com o processo produtivo que engloba também o seu trabalho.

\section{Sobre as conclusões}

Os aportes conferidos à pesquisa pela filosofia da vida cotidiana de Agnes Heller (2008) revelaramse abundantes e de longo alcance. Segundo Maria Helena S. Patto (1993), a filósofa húngara, da Escola de Budapeste, revê não apenas o sujeito da história em Marx, mas também como e onde ela se desenvolve. Resgata a subjetividade e a vida cotidiana, pouco consideradas até então pelo materialismo histórico, e as coloca no centro da história.

Heller (1982) afirma que é preciso engendrar novas formas de organização e de mediação políticas, o que significa pôr ênfase nas relações sociais cotidianas. Se a democracia formal é uma premissa para ela, a esfera macropolítica não a convence, já que a revolução é processo lento, molecular e dialético, devido à própria continuidade da vida cotidiana (Heller, 1982). A experiência da práxis, a superação possível da alienação por meio de ações transformadoras e conscientes, se dá no plano de um trabalho invisível em pequenos grupos: "Desta forma, invalida uma leitura de Marx segundo a qual há uma seqüência mecânica de modos de produção. No contexto de suas idéias, a revolução é possibilidade e não destino e se fará na vida cotidiana" (Patto, 1993, p. 132, grifo nosso).

A perspectiva teórica traçada pela da autora nos deu elementos suficientes para compreender, por exemplo, que o caso da Justa Trama representa uma viva expressão do que ela chamou de um desafio à desumanização (Heller, 2008). Ou seja, uma experiência de condução da vida levada a cabo por individualidades conscientes que buscam apropriarse da realidade de maneira não-alienada, orientadas pela realização de valores humano-genéricos. Como vimos, a experiência da Justa Trama também revelouse uma possibilidade axiológica de instituir história no cotidiano, em meio a muitos empecilhos, e também por eles, na perspectiva conceitual indicada por Agnes Heller $(1982,2008)$, de pequenos grupos, moralmente motivados, dedicados à satisfação do que chamou de carecimentos radicais. 


\section{Trabalho e política: tramas indissociáveis da autogestão}

Entre as principais conclusões da pesquisa, está ainda a consideração da experiência de autogestão da Justa Trama dialeticamente, como uma organização econômica, com fins de geração de renda, e como organização política, como um meio de resistir às mazelas do capitalismo e de buscar instituir, nos limites das circunstâncias, e junto do movimento de Economia Solidária, outro paradigma econômico pautado pela autogestão. Também vimos como a política no cotidiano da autogestão da rede pode ser entendida como inerente ao trabalho. E o trabalho, por sua vez, pode ser compreendido como objeto de prática política do grupo. Por fim, entendemos também, em companhia de Agnes Heller, que o projeto da Justa Trama, em particular, e o da Economia Solidária, em geral, encontram outra dialética, no desafio da generalização de seus projetos. De um lado, a existência deles hoje comprova que, de fato, outra economia é possível $e$ existe, como proclama o movimento, em seu lema. De outro, a generalização de suas propostas precisa ser consolidada, sob pena de comprometer a permanência histórica e os valores originais desses projetos. Em outras palavras, é impossível a um pequeno grupo, por mais predicados que reúna, por mais não-alienado que seja, em termos hellerianos, operar isoladamente grandes transformações históricas. É preciso uma organização política anti-hegemônica maior, sistêmica, capaz de operar a necessária generalização desses valores e proposições. Alguns estudiosos apontam o movimento da Economia Solidária como detentor deste potencial.

Provar que a gente é capaz de ter um controle de todo o processo de produção. Os trabalhadores organizados em Economia Solidária, de forma coletiva. ... Porque isso é mexer na estrutura da sociedade. Isso é você, de fato, construir algo que o capitalismo não te tira, nenhum outro sistema te tira. ... É importante pra gente, é importante pro mundo. ... você pode acreditar que o mundo pode mudar, não nas belas palavras, mas porque está mudando aqui, e porque também ele está mudando numa dimensão maior. ... tu mexe e consegue derrubar aqueles mitos e provar que, de fato, a sociedade só é desse jeito porque tem ganância, porque tem alguém que está ganhando sobre a exploração do outro. (Nelsa, Univens)

A projetada radicalização da democracia que aqui esboçamos parece ser demasiado utópica. Mas tantas instituições que hoje temos como coisa natural foram antes utópicas, que a associação de utopia a inexeqüibilidade é completamente injustificável. (Heller \& Fehér, 1998, p. 57)

\section{Notas}

1 O direito ao trabalho, objeto do Artigo XXIII da Declaração Universal dos Direitos Humanos (ONU), de 1948, também consta entre os direitos sociais fundamentais na Constituição Federal de 1988 (Cap. II). No entanto, sabe-se que a letra dessa lei nunca foi de fato implementada no país, como bem assinalam e discutem Patto (2009) e Sato (2009).

2 Trabalho e política são categorias prenhes de polissemias. Parte-se aqui de concepções marxistas (Marx, 1980), que tomam o trabalho dialeticamente, nas relações de transformação entre homens e natureza, e que fundamentam as proposições sobre política na obra helleriana, referencial teórico deste estudo (Heller, 2008; Heller \& Fehér, 1998).

3 Optamos por não revelar dados quantitativos alusivos ao faturamento e à produção da rede, em atenção a um pedido do grupo. Entendemos ainda que para esta pesquisa importam mais os aspectos qualitativos do desempenho econômico da Justa Trama.

4 A não-cisão entre as esferas da gestão e da produção também é característica marcante da organização da Cooperativa Univens. Foi, aliás, um dos fatores identificados na pesquisa anterior para explicar a intensa atividade política cotidiana do grupo (Andrada, 2009).

5 Não é possível apresentar aqui a diversidade da rede e de seus empreendimentos de base. Mais informações estão disponíveis na tese e em estudos nela referidos (Andrada, 2013).

6 Expressões usadas por trabalhadores da rede - "ouvir os ventos", "reconhecer os lugares" e "separar os papéis" remetem a habilidades políticas cruciais em contextos de resistência, como ler as circunstâncias e nelas identificar diferentes cenários, atores e interesses. Trata-se de coordenar senso de circunstância e estratégia, coletivamente, e assim ler e inscrever, nos tempos e espaços das interações políticas cotidianas, o que se pretende.

\section{Referências}

Andrada, C. F. (2009). O encontro da política com o trabalho: um estudo psicossocial sobre a autogestão das trabalhadoras da Univens. Porto Alegre: Abrapso Sul.

Andrada, C. F. (2010). Etnografias em Psicologia Social: notas sobre uma aproximação fecunda. Ponto.Urbe (USP), 7(1), 129.

Andrada, C. F. (2013). Trabalho e politica no cotidiano da autogestão: o caso da rede Justa Trama. Tese de Doutorado, Programa de Pós-Graduação em Psicologia Social, Universidade de São Paulo, São Paulo.

Antunes, R. (1999). Os sentidos do trabalho. São Paulo: Boitempo.

Certeau, M. (1994). A invenção do cotidiano 1: artes de fazer. Petrópolis, RJ: Vozes.

Coraggio, J. L. (2004). Una alternativa socioeconómica necesaria: la economía social. In C. Danani, Política Social y Economía Social (pp. 169-201). Buenos Aires: Altamira.

Cruz, A. (2010). A rede Justa Trama: os fios e o tecido de uma cadeia produtiva na Economia Solidária. In L. Morais \& A. Borges (Orgs.), Novos paradigmas de produção e consumo: experiências inovadoras (pp. 343-384). São Paulo: Instituto Polis. 
Dowbor, L. (1998). A reprodução social: propostas para uma gestão descentralizada. Petrópolis, RJ: Vozes.

Gaiger, L. I. (2004). (Org.). Sentidos e experiências da economia solidária. Porto Alegre: EdUFRGS - Rede Unitrabalho.

Heller, A. (1982). Para mudar a vida-felicidade, liberdade e democracia. Entrevista a Ferdinando Adornato. São Paulo: Brasiliense.

Heller, A. (2008). O cotidiano e a História. São Paulo: Paz e Terra.

Heller, A. \& Fehér, F. (1998). A condição política pós-moderna. Rio de Janeiro: Civilização Brasileira.

Leite, M. P. (2009). A economia solidária e o trabalho associativo: teorias e realidades. Revista Brasileira de Ciências Sociais, 24(69), 31-51.

Lukács, G. (2010). Prolegômenos para uma ontologia do ser social. São Paulo: Boitempo.

Magnani, J. G. C. (2009). Etnografia como prática e experiência. Horizontes Antropológicos, 15(32), 129-156.

Marcus, G. E. (1995). Ethnography in/of the word system: The emergence of multi-sited ethnography. Annual Review of Anthropology, 1(24), 95-117.

Marx, K. (1980). O capital. Rio de Janeiro: Zahar.

Metello, D. G. (2007) Os beneficios da associação em cadeias produtivas: o caso da Justa Trama - cadeia solidária do algodão agroecológico. Dissertação de Mestrado, Programa de Pós-Graduação em Engenharia, Universidade Federal do Rio de Janeiro, Rio de Janeiro.

Morais, L. \& Borges, A. (Orgs). (2010). Novos paradigmas de produção e consumo: experiências inovadoras. São Paulo: Instituto Pólis.

Oliveira, P. S. (2008). Economia Solidária: entrevista com Paul Singer. Estudos Avançados USP, 22(62), 289-314.

Oliveira, M. (2009). O dragão chinês contra a crise. Desafios do Desenvolvimento, 48(1), 20-30.

Patto, M. H. S. (1993). O conceito de cotidianidade em Agnes Heller e a pesquisa em educação. Perspectivas, 16(1), 119141.

Patto, M. H. S. (2009). Para ler as entrevistas. In M. H. S. Patto (Org.), A cidadania negada: politicas públicas e formas de viver (pp. 11-22). São Paulo: Casa do Psicólogo.

Sato, L. \& Souza, M. P. R. (2001). Contribuindo para desvelar a complexidade do cotidiano através da pesquisa etnográfica em psicologia. Psicologia USP, 12(2), 29-47.

Sato, L. (2009) Juntando pedaços. In M. H. S. Patto (Org.), $A$ cidadania negada: políticas públicas e formas de viver (pp. 23-27). São Paulo: Casa do Psicólogo.

Santos, M. (2004). Pensando o espaço do homem. São Paulo: Edusp.

Santos, M. (2008). Por uma outra globalização: do pensamento único à consciência universal. Rio de Janeiro: Record.

Singer, P. (2002). Introdução à economia solidária. São Paulo: Fundação Perseu Abramo.

Singer,P.(2004). Desenvolvimento capitalista, desenvolvimento solidário. Estudos Avançados USP, 18(51), 07-22.

Sousa-Santos, B. (2002). (Org.). Produzir para viver: os caminhos da produção não-capitalista. Rio de Janeiro: Civilização Brasileira.

Souza, A. R. (2011). Um exame da economia solidária. Otra Economía, 5(9), 173-184.

Spink, M. J. P. (2007). Pesquisando no cotidiano: recuperando memórias de pesquisa em psicologia social. Psicologia \& Sociedade, 19(1), 07-14.
Spink, P. K. (2008a). O pesquisador conversador no cotidiano. Psicologia \& Sociedade, 20(n. spe.), 70-77.

Spink, P. K. (2008b). Redes solidárias, autogestão e solidariedade. In N. Guareschi (Org.), Estratégias de invenção do presente: a psicologia social no contemporâneo (pp. 78-92). Rio de Janeiro: Centro Edelstein de Pesquisas Sociais.

\section{Agradecimento}

Esta pesquisa foi desenvolvida e defendida no Programa de Pós-Graduação em Psicologia Social da Universidade de São Paulo, sob a orientação de Leny Sato e contou com financiamento da CAPES Coordenação de Aperfeiçoamento de Pessoal de Nível Superior Processo 254554138-99.

Submissão em: 08/11/2013

Revisão em: 30/03/2014

Aceite em: 20/04/2014

Cris Fernández Andrada é Psicóloga, mestre e doutora em Psicologia Social pela Universidade de São Paulo. Endereço: Universidade de São Paulo, Instituto de Psicologia, Departamento de Psicologia Social e do Trabalho. Av. Prof. Mello Moraes, 1721 Bl. A. Cidade Universitária. São Paulo/SP, Brasil. CEP 05508900

(A/C Leny Sato) E-mail: andrada@usp.br

Leny Sato é Professora Titular do Departamento de Psicologia Social e do Trabalho do Instituto de Psicologia da Universidade de São Paulo. E-mail: lenysato@usp.br

\section{Como citar:}

Andrada, C. F. \& Sato, L. (2014). Trabalho e política no cotidiano da autogestão: a rede Justa Trama. Psicologia \& Sociedade, 26(n. spe.), 3-13. 